\title{
Extranodal presentation of Hodgkin's lymphoma of the sternum: A case report and review of the literature
}

\author{
YAN LI $^{1 *}$, YOU QIN ${ }^{1 *}$, LIDUAN ZHENG $^{2}$ and HONG LIU ${ }^{3}$ \\ ${ }^{1}$ Cancer Center; Departments of ${ }^{2}$ Pathology and ${ }^{3}$ Anesthesiology, Union Hospital, Tongji Medical College, \\ Huazhong University of Science and Technology, Wuhan, Hubei 430022, P.R. China
}

Received January 17, 2016; Accepted May 25, 2017

DOI: $10.3892 / \mathrm{ol} .2017 .7546$

\begin{abstract}
Hodgkin's lymphoma (HL) is typically a systemic disease with involvement of the cervical, supraclavicular and mediastinal lymph nodes. An extra-nodal presentation of HL is unusual and seldom encountered in the clinic. The most common sites of presentation for extra-nodal extension are the spleen, liver, lungs, bones and marrow. The bones that are frequently involved are the vertebrae, pelvis, ribs and femur. Involvement of the sternum has occasionally been reported. The current study presents an unusual case on the extra-nodal presentation of HL of the sternum arising in a 25-year-old woman, and reviews the relevant literature with particular emphasis on treatment. The extra-nodal infiltration of HL, and the clinical stage and prognosis of the case are also discussed.
\end{abstract}

\section{Introduction}

Hodgkin's lymphoma (HL) is an uncommon malignancy mainly involving the lymph nodes and the lymphatic system. The majority of patients commonly present with progressive painless enlargement of the lymph nodes, particularly around the cervical and supraclavicular lymph node regions. Extra-nodal forms of HL are rare, accounting for $<1 \%$ of all cases $(1,2)$. In late-stage HL, only $9-35 \%$ of cases have been described as presenting with osseous involvement (3). HL lesions in the bone are mostly located in the vertebrae and ribs (4), while an extra-nodal presentation in the sternum is even more rare, with nine cases clearly reported (4). The current study presents a case of HL in which sternal

Correspondence to: Professor Hong Liu, Department of Anesthesiology, Union Hospital, Tongji Medical College, Huazhong University of Science and Technology, 1277 JieFang Avenue, Wuhan, Hubei 430022, P.R. China

E-mail: liuhongwuhan@126.com

${ }^{*}$ Contributed equally

Key words: Hodgkin's lymphoma, osseous involvement, diagnose, treatment involvement was secondary to extension from the mediastinal lymph nodes. A major point of interest in this case is the obvious extra-nodal infiltration of the sternum by the mediastinal lymph node. Another aspect of interest is that this type of HL is among the most relatively benign forms, the nodular sclerosing variety, which has an improved prognosis compared with other types, including mixed cell type and lymphocyte depletion type. With current polychemotherapy and involved-field radiation therapy, the long-term prognosis of patient appears promising.

\section{Case report}

A 25-year-old woman presented with intermittent, needle-like sternal pain on December 8, 2013 and then admitted to The Cancer Center, Union Hospital of Huazhong University of Science and Technology (Wuhan, China). There was no evidence of B-symptoms; the patient was clinically well and apyrexial, with no history of night sweats or weight loss. There was no history of breathlessness.

Upon clinical examination, there was a direct tenderness on the upper middle thorax. A small (1.5 cm in diameter) mobile lymph node was found in the right supraclavicular region, and another $(3 \times 1.5 \mathrm{~cm})$ in the right axilla. Careful examination did not reveal any other palpable nodes elsewhere. The surface skin had a normal appearance and a normal temperature. No other abnormalities were found. There was no other evidence of lymphadenopathy or bone lesions.

Initial investigations revealed an elevated erythrocyte sedimentation rate $(22 \mathrm{~mm} / \mathrm{h}$. reference value is $0.00-20.00 \mathrm{~mm} / \mathrm{h})$, with a white a blood cell count of $17.41 \times 10^{9} / 1$ (normal range, $4.0-10.0 \times 10^{9} / 1$ ) and neutrophilia $14.24 \times 10^{9} / 1$ (normal range, $\left.2.00-7.00 \times 10^{9} / 1\right)$. Monocyte count $\left(1.26 \times 10^{9} / 1\right)$ was slightly increased (normal range, 0.12-0.80x $10^{9} / 1$ ). The rest of the important laboratory results were within normal limits, including creatinine, liver enzymes, alkaline phosphatase, lactate dehydrogenase (LDH) and hemoglobin levels.

A cellular bone marrow aspiration smear showed no evidence of lymphoma infiltration. Upon performing a computed tomography (CT) plain scan, the anterior middle mediastinum presented with multiple nodules of different sizes. Sternal plain and contrast-enhanced magnetic resonance imaging confirmed lymphomatous involvement of 

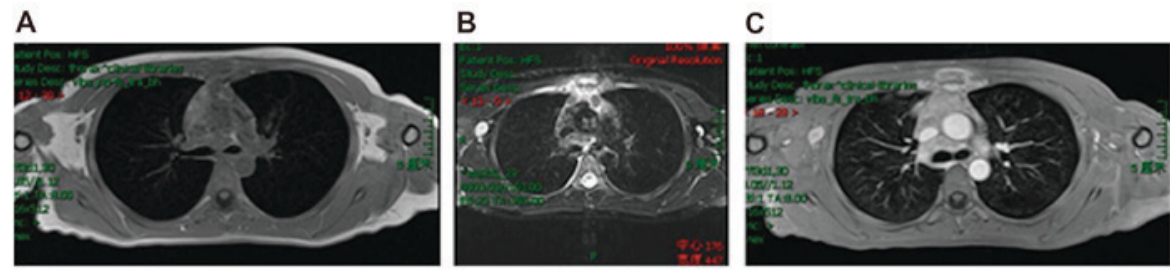

Figure 1. Axial magnetic resonance imaging of the lesions of the sternum. (A) T1-weighted image. (B) Enhanced scan of T1-weighted image demonstrating the discontinuous cortex of the posterior midsternum and the soft-tissue mass around. (C) T2-weighted image.

the sternum with slightly short T1-weighted images and slightly long T2-weighted images in the mesosternum and ensisternum. Furthermore, pathological enhancement was observed of the sternum marrow cavity and the surrounding soft-tissue shadow (Fig. 1). Positron emission tomography/computed tomography (PET/CT) revealed increased uptake in the sternum and multiple swollen lymph nodes of the right clavicle region, the right axilla, the mediastinum and the right side of sternum (Fig. 2). The fluorodeoxyglucose maximum standardized uptake value (SUVmax) of the sternum was 7.5. The lymph node SUVmax of the right clavicle region, the right axilla, the mediastinum and the right sternum aside was 2.7-3.8, 5.5 and 3.7-6.3 respectively. Clinically, an SUVmax value of $\geq 2.5$ is often regarded as a criterion for malignant lesions. These results (SUVmax $>2.5$ ) suggested that malignant lymphoma. Excluding those results, the remainder of the investigated body regions showed no signs of lymphoma infiltration.

Excisional biopsy of the cervical lymph node under local anesthesia revealed the histological features of classical HL, nodular sclerosis type (Fig. 3). Fig. 3 presents the hematoxylin and eosin stain, as well as immunohistochemistry. Tissues were fixed with $4 \%$ formol at room temperature for $50 \mathrm{~min}$, and embedded in paraffin. Sections were $4 \mu \mathrm{m}$ thick and were studied histologically with hematoxylin and eosin staining and immunohistochemistry. In brief, the process for hematoxylin and eosin staining included dewaxing with xylene for $10 \mathrm{~min}$ at $60^{\circ} \mathrm{C}$ (repeat twice), staining (hematoxylin, $2 \mathrm{~min}$ and eosin, $2 \mathrm{~min}$; at room temperature), dehydrating using graded ethanol (70\% ethanol for $2 \mathrm{~min}, 80 \%$ ethanol for $2 \mathrm{~min}$ and $95 \%$ ethanol for $2 \mathrm{~min}$ ), transparentizing, and mounting with neutral gum. For immunohistochemistry, tissue sections were deparaffinized in xylene and rehydrated in serial ethanol dilutions. For deparaffinization, tissue sections were placed in a $60^{\circ} \mathrm{C}$ thermostat for $1 \mathrm{~h}$ first and subsequently in xylene solution for $20 \mathrm{~min}$. For rehydration, sections were placed in $100 \%$ absolute ethanol for $5 \mathrm{~min}, 95 \%$ ethanol for $2 \mathrm{~min}$, $90 \%$ ethanol for $2 \mathrm{~min}, 80 \%$ ethanol for $2 \mathrm{~min}$, distilled water for 2 min and then washed using PBS for 5 mins two times. Antigen retrieval was performed through heating the tissue sections in $10 \mathrm{mM}$ sodium citrate buffer for $10 \mathrm{~min}$. Following blocking of endogenous nonspecific peroxidase activity in $3 \% \mathrm{H}_{2} \mathrm{O}_{2}$ for $15 \mathrm{~min}$, sections were then incubated in 5\% normal goat serum (Beijing ComWin Biotech Co., Ltd., Beijing, China) at room temperature for $30 \mathrm{~min}$. Tissue sections were subsequently incubated with primary antibodies (1:1 dilution), including the following antibodies for cluster of differentiation (CD)30 (cat no. MAB-0023), paired box 5 (cat no. MAB-0706), CD1a (cat no. MAB-0336), CD68 (cat no. Kit-0026), marker of proliferation Ki-67 (cat no. Kit-0005), CD15 (cat no. MAB-0015), CD21 (cat no. MAB-0339), CD20 (cat no. MAB-0669), CD3 (cat no. Kit-0003), CD23 (cat no. RMA-0504), CD34 (cat no. Kit-0004), latent membrane protein 1 (cat no. MAB-0063), ALK receptor tyrosine kinase (cat no. MAB-0281), epithelial membrane antigen (cat no. Kit-0011), smooth muscle actin (cat no. Kit-0006), D2-40 (cat no. MAB-0567) and S-100 (cat no. Kit-0007) at $4^{\circ} \mathrm{C}$ overnight followed by incubation with horseradish-peroxidase (HRP)-conjugated secondary antibody kits (Fuzhou Maixin Biotech Co., Ltd., Fuzhou, China): HRP-polymer anti-mouse IHC kit (cat no. KIT-5003) and HRP-polymer anti-rabbit IHC kit (dilution, 1:1; cat no. KIT-5006). at room temperature for $1 \mathrm{~h} .0 .025 \%$ hematoxylin was then applied for nuclear counterstaining for $1 \mathrm{~min}$ at room temperature. Primary antibodies of IHC listed in table I were all purchased from Fuzhou Maixin Biotech Co., Ltd. (Fuzhou, China). As presented in Fig. 3A, multiple cell components could be observed in eosinophils, plasmacytes, lymphocytes and atypical cells. Typical Sternberg-Reed cells and lacunar cells are presented in Fig. 3B and $\mathrm{C}$ respectively. Furthermore, the large cells were positive for CD30 identified on the surface of R-S cells in Fig. 3D. Immunohistochemically, the diagnosis of HL was confirmed (Table I). The EBER-in situ hybridisation (EBER-ISH) detection was negative. EBER-ISH was performed using a commercially available kit purchased from Zhongshan Goldenbridge Biotech Co., Ltd. (Beijing, China) according to the manufacturer protocol. Briefly, tissue sections were dewaxed, endogenous peroxidase activity was blocked by incubating in $3 \% \mathrm{H}_{2} \mathrm{O}_{2}$ in methanol for 5 min and tissues digested with $100 \mu \mathrm{g} / \mathrm{ml}$ proteinase $\mathrm{K}$ for $5 \mathrm{~min}$ at $37^{\circ} \mathrm{C}$. Subsequently sections were dehydrated and hybridised overnight at $42^{\circ} \mathrm{C}$ using a mixture of digoxigenin-labeled EBER-1/2 anti-sense oligonucleotide probes. The hybridized probes were detected using the HRP-anti-digoxin monoclonal antibody and diaminobenzidine tetrahydrochloride (DAB) was used as a chromogen. All results were in accordance with $\mathrm{HL}$ and infiltration of the sternum.

Therefore, the clinical diagnosis was of classical HL (nodular sclerosis type) involving infiltration of the sternum, stage IIE, A category (localized involvement of an extra-lymphatic organ or site and of one or more lymph node regions on the same side of the diaphragm, with no systemic symptoms of fever, night sweats or weight loss). As the imaging studies and excisional lymph node biopsy showed HL and infiltration of the sternum, a biopsy of the sternal lesion was not performed.

The patient's International Prognostic Index (5) score was zero; the patient was aged $<60$ years, with an Eastern Cooperative Oncology Group score (6) of 1, stage II 


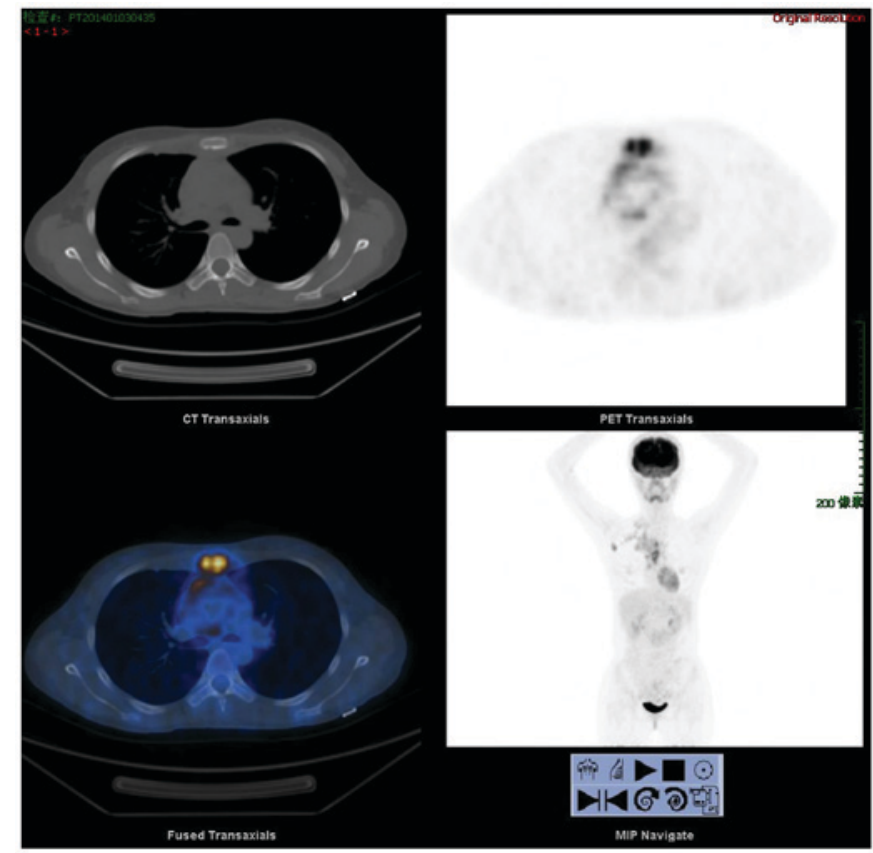

Figure 2. Positron emission tomography/computed tomography at the time of presentation demonstrating increased fluorodeoxyglucose uptake in the sternum.
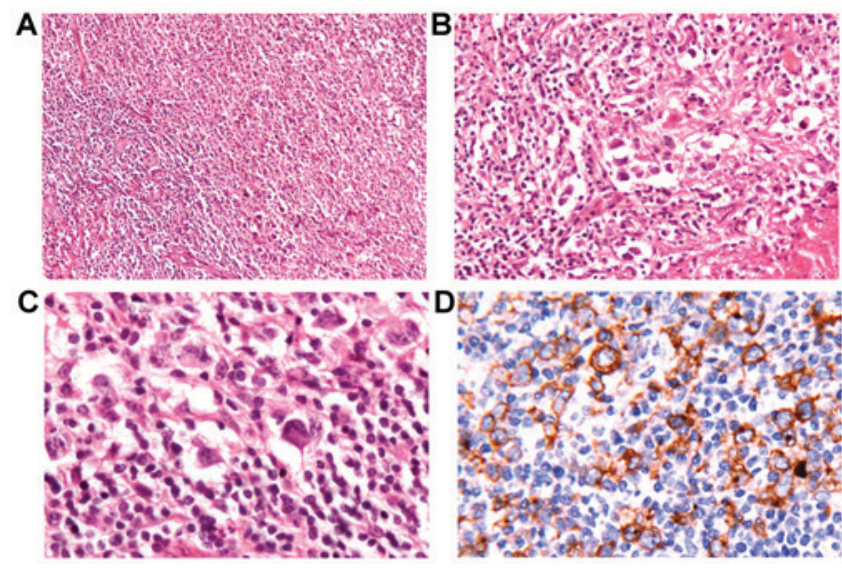

Figure 3. (A) Background mixture of eosinophils, plasmacytes, lymphocytes and atypical cells. (B) Typical R-S cells are apparent. (C) Occasional lacunar cells are also apparent. (D) The large cells are positive for cluster of differentiation 30 found on the surface of R-S cells. R-S, Reed-Sternberg.

disease, one extra-nodal site (sternum) and an LDH level within the normal range. The risk assessment was classified as low level.

According to the National Comprehensive Cancer Network (7) guidelines (Version 2016, Hodgkin lymphoma), for stage I to II patients with unfavorable disease, chemotherapy is recommended [4-6 cycles of an adriamycin, bleomycin, vinblastine and dacarbazine (ABVD) or Stanford V regimen] followed by involved-field radiation therapy (IFRT). The patient was recommended to undergo 6 cycles of standard-dose chemotherapy with ABVD, which consisted of adriamycin $25 \mathrm{mg} / \mathrm{m}^{2}$ [days 1 and 15, intravenous injection (i.v.)], bleomycin $10 \mathrm{mg} / \mathrm{m}^{2}$ (days 1 and 15, i.v.), vinblastine $6 \mathrm{mg} / \mathrm{m}^{2}$ (days 1 and 15, i.v.) and dacarbazine $375 \mathrm{mg} / \mathrm{m}^{2}$ (days 1 and 15, i.v.). One cycle of ABVD chemotherapy was given over 4 weeks.
Table I. Final results of IHC and ISH assessment.

\begin{tabular}{lc}
\hline Assessment & Result \\
\hline IHC & \\
CD30 & $(+)$ \\
Pax5 & $(+)$ \\
CD1a & (histocyte+) \\
CD68 & (histocyte+) \\
Ki-67 & $($ oncocyte+) \\
CD15 & $(-)$ \\
CD21 & $(-)$ \\
CD20 & $(-)$ \\
CD3 & $(-)$ \\
CD23 & $(-)$ \\
CD34 & $(-)$ \\
LMP1 & $(-)$ \\
ALK & $(-)$ \\
EMA & $(-)$ \\
SMA & $(-)$ \\
D2-40 & $(-)$ \\
S-100 & $(-)$ \\
EBH & \\
\hline EB & $(-)$ \\
\hline
\end{tabular}

$\mathrm{Ki}-67$ protein is a cellular marker for proliferation; D2-40 is a marker of lymphatic endothelial cells, reflecting micro lymphatic vessel density; S-100 protein family are useful as markers for certain tumors and epidermal differentiation. IHC, immunohistochemistry; ISH, in situ hybridization; CD, cluster of differentiation; Pax5, Paired box protein Pax-5; LMP1, latent membrane protein 1; ALK, ALK tyrosine kinase receptor; EMA, epithelial membrane antigen; SMA, smooth muscle actin; EBER, Epstein Barr virus encoded small RNA.

Subsequent to the first cycle of chemotherapy (January 7 and $21,2014)$, the symptom of sternal pain improved immediately and markedly. PET-CT after the second cycle was negative, showing no evidence of hypermetabolic nodules or regions. The curative effect evaluation was of complete remission. Finally, the patient refused the sixth chemotherapy cycle due to personal reasons. Following completion of the chemotherapy, consolidative IFRT of the mediastinum and sternum was performed.

Follow-up PET-CT subsequent to all treatment once again returned negative results and the patient achieved complete remission. Almost 6 months after therapy, the patient was found to be well without any signs of local recurrence or any further lymph node metastasis. At present (42 months until November 2017), the patient remains disease-free. Written consent was obtained from the patient for publication of this case report.

Literature review. A literature review of the osseous involvement of HL indicates that the majority of cases have been associated with local or distant lymph node involvement. Osseous involvement of HL presenting as a sternal lesion is 
Table II. Cases in the literature that presented with osseous involvement of Hodgkin's lymphoma.

\begin{tabular}{|c|c|c|c|c|c|c|}
\hline $\begin{array}{l}\text { First } \\
\text { author, year }\end{array}$ & $\begin{array}{l}\text { Age, } \\
\text { years }\end{array}$ & Gender & Site(s) & Therapy & Outcome & (Refs.) \\
\hline Eustace et al, 1995 & 63 & M & $\begin{array}{l}\text { Left proximal femur, } \\
\text { right iliac wing }\end{array}$ & Chemo & $\begin{array}{l}\text { NED } \\
\text { (6 months) }\end{array}$ & $(12)$ \\
\hline Fried et al, 1995 & 21 & $\mathrm{~F}$ & Left lateral clavicle & Chemo & $\begin{array}{l}\text { NED } \\
\text { (36 months) }\end{array}$ & (13) \\
\hline Citow, et al, 2001 & 54 & $\mathrm{~F}$ & $\mathrm{~T} 4, \mathrm{~T} 5$ & $\begin{array}{l}\text { Surgery + } \\
\text { chemo + IRF }\end{array}$ & $\begin{array}{l}\text { AWD } \\
\text { (36 months) }\end{array}$ & (14) \\
\hline Gebert et al, 2005 & 21 & M & $\begin{array}{l}\text { Right proximal femur, } \\
\text { right proximal tibia }\end{array}$ & $\begin{array}{l}\text { Curettage + } \\
\text { chemo + IRF }\end{array}$ & $\begin{array}{l}\text { NED } \\
\text { (4 years) }\end{array}$ & $(15)$ \\
\hline Langley et al, 2008 & 7 & M & $\begin{array}{l}\text { Sternum, L1 vertebra, the left } \\
\text { sacro-iliac joint and the } \\
\text { right acetabulum }\end{array}$ & Chemo & AWD & $(16)$ \\
\hline Chandra et al, 2006 & 51 & $\mathrm{~F}$ & Left ileum & Chemo + IRF & Alive & $(17)$ \\
\hline Biswas et al, 2008 & 21 & M & Sternum & Chemo + IRF & $\begin{array}{l}\text { After PD gave } \\
\text { salvage chemo }\end{array}$ & (4) \\
\hline Li et al, 2012 & 38 & $\mathrm{~F}$ & Right second rib & Chemo + IRF & Alive & (18) \\
\hline Binesh et al, 2012 & 63 & $\mathrm{~F}$ & L2 to L5 vertebra & Chemo & Alive & (19) \\
\hline Present study & 25 & $\mathrm{~F}$ & Sternum & Chemo + IRF & $\begin{array}{l}\text { NED (42 months, } \\
\text { until Nov. 2017) }\end{array}$ & \\
\hline
\end{tabular}

Chemo, chemotherapy; IRF, involved field radiotherapy; NED, no evidence of disease; AWD, alive with disease; PD, progressive disease; M, male; F, female.

quite unusual. In 1999, Ostrowski et al (8) reported that only 3 cases among 25 patients with osseous involvement of HL showed sternal involvement. Toussirot et al (9) reported that in 10 cases of anterior chest wall malignancies, 2 were due to osseous HL. In another retrospective review reported by Franczyk et al (10), 3 out of 42 patients with HL (2 with mixed cellularity type and 1 with nodular sclerosis type) had sternal lesions, all from direct extension from mediastinal lymph nodes. Another case of HL with unusual sternal presentation has also been reported in India (11).

Table II summarizes the clinical characteristics of the patients with osseous involvement of HL in recent years $(4,12-19)$. The bones most frequently involved were the vertebrae, ribs, femur and sternum. Through chemotherapy and radiation, most patients could achieve complete remission. The outcome of the patients was usually a good prognosis.

Radiotherapy alone was a standard treatment option for patients with favorable early-stage HL for a number of decades (20). However, the potential long-term toxicities of a high-dose and large-field irradiation include an increased risk for heart disease, pulmonary dysfunction and secondary cancer (21). For this reason, many investigators have been contemplating the use of chemotherapy alone as a treatment modality.

Now, in comparison to a single treatment type, the use of combined modality therapy (IFRT plus chemotherapy) has considerably improved the patient outcome and is the current gold standard of treatment (22-24). The past few years have witnessed significant progress in the management of HL; it is now curable in at least $80 \%$ of patients (25).
Newcomer et al (22) reported that of the 18 patients of osseous HL treated with combined modality therapy, only 3 were induction failures and the condition of 1 patient was subsequently salvaged with additional therapy. According to Mendenhall et al (26), radiotherapy should be delayed until the completion of chemotherapy to reduce the dose and volume of radiation, which can of course reduce the number of adverse events (26).

\section{Discussion}

HL is an uncommon malignancy mainly involving the lymph nodes and the lymphatic system. An extranodal presentation of HL is unusual and the most common sites of presentation for extranodal extension are the spleen, liver, lungs, bones and marrow. However, such instances are seldom observed in the clinic. The bones frequently involved are the vertebrae, pelvis, ribs and femur $(4,8,22,27,28)$. Involvement of the sternum has occasionally been reported $(4,8,27)$.

Osseous involvement may be either due to primary lymphoma of the bone or may be secondary to hematogenous or direct contiguous spread from the lymph nodes and a soft-tissue mass $(22,28)$. Primary osseous HL is a heterogeneous group of disorders. There should not be any signs or symptoms of systemic disease at the time of presentation or at the time of staging. Primary osseous HL is defined as malignant lymphoid infiltration within the bones, with or without cortical invasion or extension into contiguous soft tissues, and without involvement of regional lymph nodes or distant viscera within 6 months of presentation $(23,29)$. The case of sternal 
involvement in the present study was secondary to extension, reflecting direct extension from the mediastinal lymph nodes into the sternum.

The clinical stage has a critical role in the selection of treatment. According to Ann Arbor staging (30), stage IV adult HL is characterized by disseminated (multifocal) involvement of one or more extra-lymphatic organs, with or without associated lymph node involvement, or isolated extra-lymphatic organ involvement with distant (non-regional) nodal involvement.

In the past, scholars believed that bone involvement heralds disease progression. Osseous infiltration usually indicates widespread disease (16). Therefore, cases with osseous involvement should be classified as stage IV. However, certain individuals now consider the bone as just an extra-lymphatic organ (31). A solitary lymph node tumor may cause changes in the adjacent bone by pressure or direct invasion (29). Direct extension from a contiguous lymph node does not constitute stage IV disease, but rather an 'E' classification with a better prognosis $(31,32)$. Certain clinicians have reached the consensus that osseous involvement per se is not an adverse prognostic factor $(8,22,24,27)$.

Taking the aforementioned into consideration, the sternal infiltration of HL in the present study was diagnosed as stage IIE disease. A major point of interest in this case is the marked extra-nodal infiltration of the sternum by the mediastinal lymph node. Another point of interest is that this type of HL is among the most relatively benign forms, the nodular sclerosing variety, which has a better prognosis than the other type.

It is worth mentioning that in the era of biological imaging, whole-body PET-CT is gaining increasing attention. Compared with other methods, the advantage of PET-CT is the early detection of disease, as biochemical changes in the tumor microenvironment occur long before gross morphological alteration $(28,33)$. PET-CT scanning has been used for the initial staging, restaging and follow-up of patients with lymphoma (34). In a previous meta-analysis, PET-CT demonstrated high positivity and specificity when used to stage and restage patients with lymphoma (35). PET-CT is widely used during and after therapy for the assessment of response (36). Early interim PET-CT scans after 2-4 cycles of standard-dose chemotherapy have also been shown to be a sensitive prognostic indicator in patients with advanced stage and extra-nodal disease (37-39). The 2-year progression-free survival rate has been recorded to be significantly higher for patients with negative PET-CT results after 2 cycles of ABVD compared with that for patients with positive PET-CT results (95 vs. 13\%) (40).

In conclusion, the present case study describes an unusual extra-nodal presentation of HL. The patient responded well to IFRT combined with ABVD chemotherapy, resulting in apparently complete remission of the tumor without further evidence of local recurrence or spread of the disease. The requirement for rapid histological and immunocytochemical examination in patients should be stressed in order to prevent systemic dissemination. With current polychemotherapy, the long-term prognosis of affected patients appears good.

\section{Acknowledgements}

The present study was financially supported by the National Natural Science Foundation of China (grant no. 81202962).

\section{References}

1. Guermazi A, Brice P, de Kerviler E E, Fermé C, Hennequin C, Meignin V and Frija J: Extranodal Hodgkin disease: Spectrum of disease. Radiographics 21: 161-179, 2001.

2. Zucca E: Extranodal lymphoma: A reappraisal. Ann Oncol 19 (Suppl 4): iv77-iv80, 2008.

3. Chan KW, Rosen G, Miller DR and Tan CT: Hodgkin's diseases in adolescents presenting as a primary bone lesion. A report of four cases and review of literature. Am J Pediatr Hematol Oncol 4: 11-17, 1982.

4. Biswas A, Puri T, Goyal S, Haresh KP, Gupta R, Julka PK and Rath GK: Osseous Hodgkin's lymphoma-review of literature and report of an unusual case presenting as a large ulcerofungating sternal mass. Bone 43: 636-640, 2008.

5. The International Non-Hodgkin's Lymphoma Prognostic Factors Project: A predictive model for aggressive non-Hodgkin's lymphoma. N Engl J Med 329: 987-994, 1993.

6. Oken MM, Creech RH, Tormey DC, Horton J, Davis TE, McFadden ET and Carbone PP: Toxicity and response criteria of the Eastern Cooperative Oncology Group. Am J Clin Oncol 5: 649-655, 1982.

7. National Comprehensive Cancer and Network (NCCN): NCCN Guidelines for Patients ${ }^{\circledR}$. Version 2016: Hodgkin Lymphoma. NCCN, Fort Washington, PA, 2016.

8. Ostrowski ML, Inwards CY, Strickler JG, Witzig TE, Wenger DE and Unni KK: Osseous Hodgkin disease. Cancer 85: 1166-1178, 1999.

9. Toussirot E, Gallinet E, Augé B, Voillat L and Wendling D: Anterior chest wall malignancies. A review of ten cases. Rev Rhum Engl Ed 65: 397-405, 1998.

10. FranczykJ,Samuels T,Rubenstein J,Srigley J and Morava-Protzner I: Skeletal lymphoma. Can Assoc Radiol J 40: 75-79, 1989.

11. Meher-Homji DR, De Souza LJ, Mohanty B and Culcuttawalla TF: Unusual sternal mass in Hodgkin's disease. A case report. J Bone Joint Surg Am 54: 402-404, 1972.

12. Eustace S, O'Regan R, Graham D and Carney D: Primary multifocal skeletal Hodgkin's disease confined to bone. Skeletal Radiol 24: 61-63, 1995.

13. Fried G, Ben Arieh Y, Haim N, Dale J and Stein M: Primary Hodgkin's disease of the bone. Med Pediatr Oncol 24: 204-207, 1995.

14. Citow JS, Rini B, Wollmann R and Macdonald RL: Isolated, primary extranodal Hodgkin's disease of the spine: Case report. Neurosurgery 49: 453-457, 2001.

15. Gebert C, Hardes J, Ahrens H, Buerger H, Winkelmann W and Gosheger G: Primary multifocal osseous Hodgkin disease: A case report and review of the literature. J Cancer Res Clin Oncol 131: 163-168, 2005.

16. Langley CR, Garrett SJ, Urand J, Kohler J and Clarke NM: Primary multifocal osseous Hodgkin's lymphoma. World J Surg Oncol 6: 34, 2008.

17. Chandra D, Ewton A and Baker K: Hodgkin's disease presenting with osseous involvement. Am J Hematol 81: 550-551, 2006.

18. Li Y, Wang XB, Tian XY, Li B and Li Z: Unusual primary osseous Hodgkin lymphoma in rib with associated soft tissue mass: A case report and review of literature. Diagn Pathol 7: 64, 2012.

19. Binesh F, Mirjalili MR, Akhavan A and Navabii H: Primary bony Hodgkin's lymphoma. BMJ Case Rep 2012: pii: bcr0120125714, 2012.

20. Dühmke E, Franklin J, Pfreundschuh M, Sehlen S, Willich N, Rühl U, Müller RP, Lukas P, Atzinger A, Paulus U, et al: Low-dose radiation is sufficient for the noninvolved extended-field treatment in favorable early-stage Hodgkin's disease: Long-term results of a randomized trial of radiotherapy alone. J Clin Oncol 19: 2905-2914, 2001.

21. Gustavsson A, Osterman B and Cavallin-Ståhl E: A systematic overview of radiation therapy effects in Hodgkin's lymphoma. Acta Oncol 42: 589-604, 2003.

22. Newcomer LN, Silverstein MB, Cadman EC, Farber LR, Bertino JR and Prosnitz LR: Bone involvement in Hodgkin's disease. Cancer 49: 338-342, 1982.

23. Dürr HR, Müller PE, Hiller E, Maier M, Baur A, Jansson V and Refior HJ: Malignant lymphoma of bone. Arch Orthop Trauma Surg 122: 10-16, 2002

24. Borg MF, Chowdhury AD, Bhoopal S and Benjamin CS: Bone involvement in Hodgkin's disease. Australas Radiol 37: 63-66, 1993.

25. Gustavsson A, Osterman B and Cavallin-Ståhl E: A systematic overview of radiation therapy effects in non-Hodgkin's lymphoma. Acta Oncol 42: 605-619, 2003. 
26. Mendenhall NP, Jones JJ, Kramer BS, Hudson TM, Carter RL, Enneking WF, Marcus RB Jr and Million RR: The management of primary lymphoma of bone. Radiother Oncol 9: 137-145, 1987.

27. Feltl D, Marková J and Kozák T: Skeletal involvement in Hodgkin's lymphoma-personal experience. Vnitr Lek 50: 134-138, 2004 (In Czech).

28. Israel O, Mekel M, Bar-Shalom R, Epelbaum R, Hermony N, Haim N, Dann EJ, Frenkel A, Ben-Arush M and Gaitini D: Bone lymphoma: $67 \mathrm{Ga}$ scintigraphy and CT for prediction of outcome after treatment. J Nucl Med 43: 1295-1303, 2002.

29. Dosoretz DE, Raymond AK, Murphy GF, Doppke KP, Schiller AL, Wang CC and Suit HD: Primary lymphoma of bone: The relationship of morphologic diversity to clinical behavior. Cancer 50: 1009-1014, 1982.

30. Carbone PP, Kaplan HS, Musshoff K, Smithers DW and Tubiana M: Report of the committee on Hodgkin's disease staging classification. Cancer Res 31: 1860-1861, 1971.

31. Parker BR, Marglin S and Castellino RA: Skeletal manifestations of leukemia, Hodgkin disease, and non-Hodgkin lymphoma. Semin Roentgenol 15: 302-315, 1980.

32. Pear BL: Skeletal manifestations of the lymphomas and leukemias. Semin Roentgenol 9: 229-240, 1974.

33. Moog F, Kotzerke J and Reske SN: FDG PET can replace bone scintigraphy in primary staging of malignant lymphoma. J Nucl Med 40: 1407-1413, 1999.

34. Seam P, Juweid ME and Cheson BD: The role of FDG-PET scans in patients with lymphoma. Blood 110: 3507-3516, 2007.

35. Isasi CR, Lu P and Blaufox MD: A metaanalysis of 18F-2-deoxy-2-fluoro-D-glucose positron emission tomography in the staging and restaging of patients with lymphoma. Cancer 104: 1066-1074, 2005.

36. Juweid ME: Utility of positron emission tomography (PET) scanning in managing patients with Hodgkin lymphoma. Hematology Am Soc Hematol Educ Program: 259-265, 510-511, 2006.
37. Gallamini A, Rigacci L, Merli F, Nassi L, Bosi A, Capodanno I, Luminari S, Vitolo U, Sancetta R, Iannitto E, et al: The predictive value of positron emission tomography scanning performed after two courses of standard therapy on treatment outcome in advanced stage Hodgkin's disease. Haematologica 91: 475-481, 2006.

38. Gallamini A, Hutchings M, Avigdor A and Polliack A: Early interim PET scan in Hodgkin lymphoma: Where do we stand? Leuk Lymphoma 49: 659-662, 2008.

39. Terasawa T, Lau J, Bardet S, Couturier O, Hotta T, Hutchings M, Nihashi T and Nagai H: Fluorine-18-fluorodeoxyglucose positron emission tomography for interim response assessment of advanced-stage Hodgkin's lymphoma and diffuse large B-cell lymphoma: A systematic review. J Clin Oncol 27: 1906-1914, 2009.

40. Gallamini A, Hutchings M, Rigacci L, Specht L, Merli F, Hansen M, Patti C, Loft A, Di Raimondo F, D'Amore F, et al: Early interim 2-[18F]fluoro-2-deoxy-D-glucose positron emission tomography is prognostically superior to international prognostic score in advanced-stage Hodgkin's lymphoma: A report from a joint Italian-Danish study. J Clin Oncol 25: 3746-3752, 2007.

(i) $($ This work is licensed under a Creative Commons Attribution-NonCommercial-NoDerivatives 4.0 International (CC BY-NC-ND 4.0) License. 